\title{
Steroidal Plant Growth Promoters vs. Phytopathogens, via Enzymatic Regulation; An in Silico Approach
}

\author{
Alan Carrasco-Carballo1* ${ }^{*}$ Emiliano Marín-Merino1, Penélope Merino-Montiel2, \\ Blanca Colin-Lozano², Sandra Luz Cabrera Hilerio³, Jazmin Ciciolil Hilario-Martínez ${ }^{4}$, \\ Jesús Sandoval-Ramírez ${ }^{1,2^{*}}$
}

${ }^{1}$ Laboratorio de Elucidación y Síntesis en Química Orgánica, Facultad de Ciencias Químicas, Benemérita Universidad Autónoma de Puebla, Puebla, México

${ }^{2}$ Laboratorio de Síntesis y Modificación de Productos Naturales, Facultad de Ciencias Químicas, Benemérita Universidad Autónoma de Puebla, Puebla, México

${ }^{3}$ Laboratorio de Bromatología, Facultad de Ciencias Químicas, Benemérita Universidad Autónoma de Puebla, Puebla, México

${ }^{4}$ Facultad de Estudios Superiores-Zaragoza, UNAM, CDMX, México

Email: *alan.carrascoc@correo.buap.mx, jesus.sandoval@correo.buap.mx

How to cite this paper: Carrasco-Carballo, A., Marín-Merino, E., Merino-Montiel, P., Colin-Lozano, B., Hilerio, S.L.C., HilarioMartínez, J.C. and Sandoval-Ramírez, J. (2021) Steroidal Plant Growth Promoters vs. Phytopathogens, via Enzymatic Regulation; An in Silico Approach. Advances in Enzyme Research, 9, 55-71.

https://doi.org/10.4236/aer.2021.94006

Received: October 20, 2021

Accepted: November 22, 2021

Published: November 25, 2021

Copyright $\odot 2021$ by author(s) and Scientific Research Publishing Inc. This work is licensed under the Creative Commons Attribution International License (CC BY 4.0).

http://creativecommons.org/licenses/by/4.0/

\begin{abstract}
Steroidal plant growth promoters (SPGP) have been continuously studied due to their high activity increasing biomass and resistance to diverse stress factors. In our hands, a new SPGP family of 22-oxocholestanic compounds stands out at a comparative level to brassinosteroids (BSs). The potential activity of new SPGP against phytopathogens was studied through in silico molecular docking, these assays were performed with relevant ensymes of phytopatogens Chitinase B and 1,3- $\beta$-Glucanase. Nine Chitinase B inhibitors and two $1,3-\beta$-Glucanase inhibitors were proposed. The launched study analyzed the interactional and spatial level, determining the presence of interactions with key amino acids in receptors in comparison to reference inhibitors. Even more, the AVR4 and ECP6 effectors were also examined. No compound that blocks ECP6 was found; due to, probably, the influence of its highly hydrophilic environment. In the case of AVR4, two SPGP showed a better docking score (DS) than a chitin fragment (endogenous ligand); this fact demonstrates the latent potential of the 22-oxocholestanic derivatives against phytopathogens, with a specific regulation via proliferation inhibition. Moreover, this SPGP does not affect the symbiotic fungi that are beneficial for the natural plant system.
\end{abstract}

\section{Keywords}

22-Oxocholestanes, Brassinosteroids, Chitinase B, 1,3- $\beta$-Glucanase, ARV4, ECP6 


\section{Introduction}

Plant growth promoters are compounds commonly called phytohormones, which are responsible for important roles, as regulation processes for increasing biomass, flowering, resistance to stress conditions, among others. A highly active group of growth promoters are Brassinosteroids; for example, brassinolide (1) has shown a huge promoter effect than other kinds of phytohormones and resistance for abiotic stresses, this discovery has led to an increased interest in the synthesis of diverse BSs analogues, but in most cases low yields have been reported [1]-[8]. Compounds of the novel family of 22-oxocholestanes (SPGP1, SPGP3, SPGP5), (Figure 1) have been positioned as SPGP alternative due to its comparable or even more potent activity to that of BSs and moreover, can be generated through higher reaction yields. Some 22-oxocholestanes have been successfully tested in rice, red-beans, and maize [9] [10] [11]. Although these compounds have demonstrated an exceptional plant growth promoting effect in in vitro and greenhouse assays, for field tests and future applications it is necessary to predict synergistic effects on beneficial/non-beneficial phytopathogens and to study their effect on the intrinsic defense system of vegetal models.

Plants have developed several mechanisms to recognize microbial infections and respond appropriately by activating defense responses [12]. Therefore, the knowledge of the relationship between plants and the pathogenic hosts is crucial for their control [13]. It has been found that the interaction that takes place between guest and host is carried out by means of special proteins, which have effects on both cells and phenotypes of hosts [14] (Table 1). Fortunately, all plant cells possess a sophisticated surveillance system that can register and distinguish many signals of different origins, which manages to induce a more efficient and

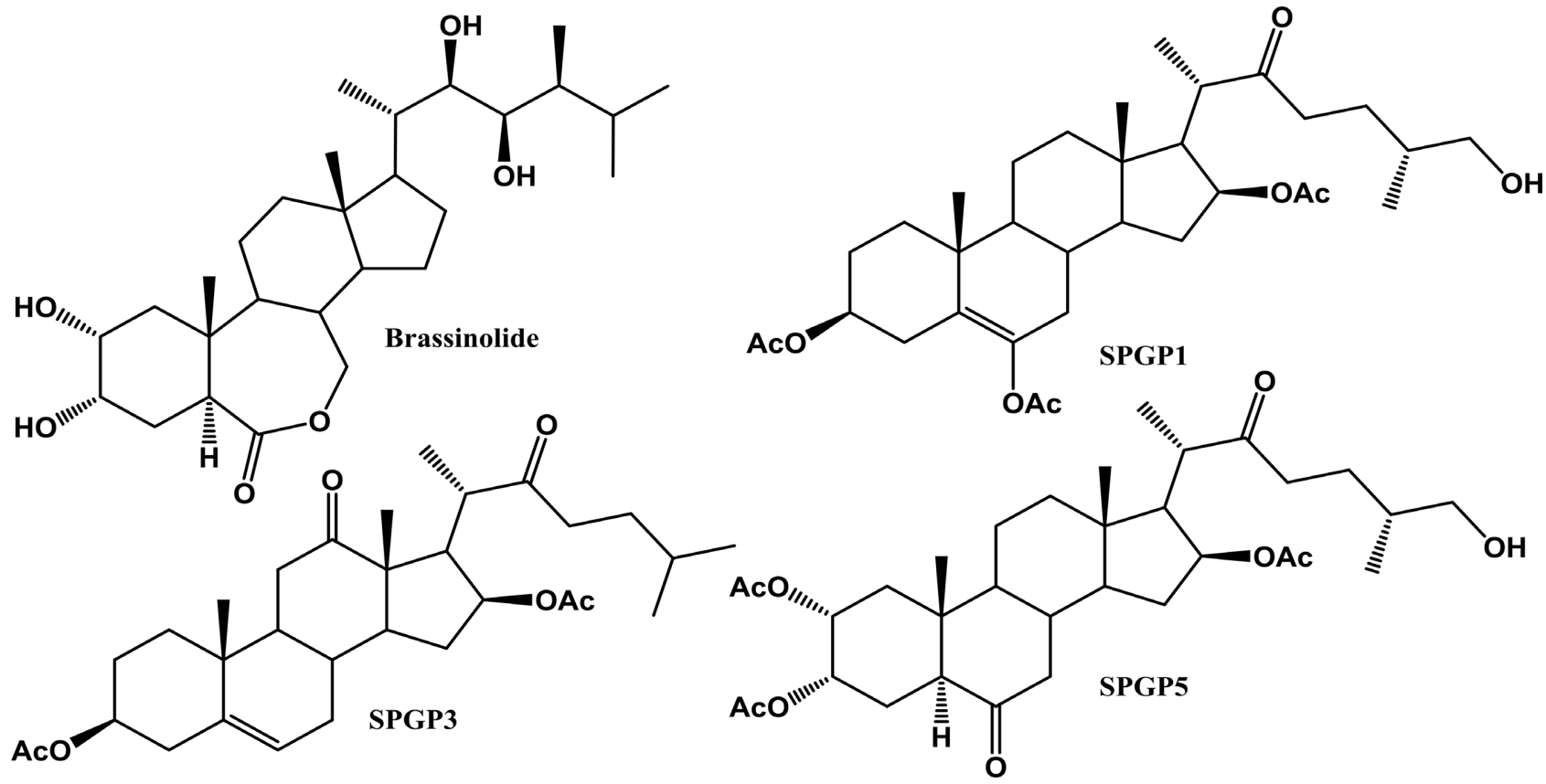

Figure 1. Steroidal derivatives providing plant growth promotion effect. 
Table 1. Proteins associated with the proliferation of phytopathogens.

\begin{tabular}{|c|c|c|c|c|}
\hline Enzyme/Protein & Function & $\begin{array}{l}\text { Reference } \\
\text { compound }\end{array}$ & Hosts & Ref. \\
\hline Chitinase B & $\begin{array}{l}\text { To hydrolyze the polymeric chitin of } \\
\mathrm{N} \text {-acetylglucosamine framework. Together with } \\
\text { the } \beta \text {-1,3-glucanases plays an indirect defensive } \\
\text { role: the oligosaccharides of } 1,3-\beta \text {-/1,6-glucan are } \\
\text { destroyed in pathogens cell walls. Inhibition of } \\
\text { the fungi growth is produced, and a wide range of } \\
\text { defense responses are induced in plants. }\end{array}$ & $\begin{array}{l}\text { Chitin (S) } \\
\text { F0O (I) }\end{array}$ & $\begin{array}{l}\text { Alternaria brassicicola } \\
\text { Sclerotinia sclerotiorum } \\
\text { Rhizoctonia solani }\end{array}$ & $\begin{array}{l}{[19][20]} \\
{[21]}\end{array}$ \\
\hline $\begin{array}{l}1,3-\beta- \\
\text { Glucanase }\end{array}$ & $\begin{array}{l}\text { To perform their protective function by a } \\
\text { hydrolysis of the } 1,3-\beta-/ 1,6 \text {-glucan bond present } \\
\text { in the pathogens cell walls. }\end{array}$ & $\begin{array}{l}1,3-\beta-/ 1,6- \\
\text { glucane }(\mathrm{S}) \\
\text { Apegin }(\mathrm{I})\end{array}$ & $\begin{array}{l}\text { Fusarium } \\
\text { moniliforme } \\
\text { F. verticillioides } \\
\text { Aspergillus } \\
\text { Flavus } \\
\text { Alternaria solani } \\
\text { Colletotrichum fragariae } \\
\text { C. acutatum }\end{array}$ & $\begin{array}{l}{[22][23]} \\
{[24][25]}\end{array}$ \\
\hline ECP6 & $\begin{array}{l}\text { Recognition of specific sequences. It encodes } \\
\text { three domains of lysine that disrupt } \\
\text { chitin-triggered immunity. }\end{array}$ & Chitin (L) & Cladosporium. fulvum & {$[18]$} \\
\hline AVR4 & $\begin{array}{l}\text { A chitin-binding lectin that protects fungal cell } \\
\text { walls from plant chitinases, providing a defensive } \\
\text { role during infection. It inhibits the Cys-protease } \\
\text { Rcr3 secreted by tomato plants and binds } \\
\text { chitinases at the fungus cell wall. }\end{array}$ & Chitin (L) & Cladosporium. fulvum & {$[26]$} \\
\hline
\end{tabular}

effective defense response at the infection site [15].

There is a special class of proteins of low molecular mass, diverse chemical composition having a different hydrophilic character that is directly related to the pathogenic fungi activity, known as Pathogenesis-Related (PR or pathogenicity proteins), such as chitinases and 1,3- $\beta$-glucanases [16]. Another unique kind of proteins that acts as a defense mechanism in plants is named effectors, like AVR4 and EPC6 [17]. When these molecules are recognized by the plant, an unfavorable interaction between the plant and pathogens, therefore, the effectors' function has not been clearly clarified [18].

In the present work, fifteen 22-oxocholestanic SPGP, which previously showed a positive experimental results as growth promoters [9] [10] (Figure 2), were in silico studied on the effect in the two principal enzymes involved in fungal proliferation (Chitinase B and 1,3- $\beta$-Glucanase). Also, the influence against two effectors of infection in plant systems (AVR4 and ECP6) was studied, to prove the potential of SPGP in fungal pests.

\section{Materials and Methods}

\subsection{Protein and Ligands Preparation}

The enzymes used were obtained from the protein data bank (PDB) with codes 
7CB1 (Chitinase B), 3N9K (1,3- $\beta$-Glucanase), 6BN0 (AVR4) and 4B8V (ECP6) [27] [28] [29] [30]. They were processed with the Protein Preparation Assistant [31] [32] using the Schrödinger Suite. Structural integrity was reviewed and adjusted; missing recurrences and loop segments near the active site were added by Prime. Hydrogen atoms were added to each protein to returned it to its original state. The protonation and tautomeric states of Asp, Glu, Arg, Lys and His were adjusted to a $\mathrm{pH}$ of 7.4. The water molecules were removed within a $5 \AA$ sphere at the active site. The orientation of the hydrogen bonds was adjusted around the active site using PROPKA at a $\mathrm{pH}$ of 7.4. Finally, the protein-ligand complex was minimized using the OPLS4 force field [33], with a convergence of heavy atoms with an RMSD of $0.3 \AA$.

Reference ligands (substrates, inhibitors, endogenous ligands) were obtained from crystals. 22-oxocholestane steroidal derivatives were designed according to the 2D Sketcher program of the Master program in Schrödinger Suite, and converted to their most stable 3D conformer. For molecular docking, ligands were prepared using LigPrep [34] from Schrödinger Suite. After of 3D structures were generated, the OPLS4 force field and the loads were prepared in all stages. All possible protonated centers and ionization states were calculated for the scaffold using ionizer at $\mathrm{pH}$ 7.4. The stereoisomers were retained according to their original structures limited to 32 isomers for each ligand. Tautomeric states were generated for each group. The conformers with the best energy were selected for each ligand.

\subsection{Docking Protocol}

Molecular docking between catalytic sites and substrates was performed using the Glide module [35] [36] from Maestro 12.2 and the receptor grid for each target was prepared using OPLS4. Each grid was built based on co-crystallized reference inhibitors or ligands. The softening of the non-polar parts of the receivers was carried out by scaling the van der Waals radii by a 0.8 factor. Atoms were considered as nonpolar if their absolute partial atomic charge was determined to be $<0.25$. In flexibility, additional ligand rotations were allowed for the hydroxyl groups at Ser, Thr, and Tyr, and the thiol group at the Cys residues. Furthermore, the lowest binding position of each ligand was maintained. Slip coupling scores were performed in three high-throughput virtual detection modes (HTVS), standard precision (SP), and additional precision (XP). Before SPGP were coupling, the coupling with reference molecules of the respective target proteins was performed to validate the coupling protocol by limiting RMSE as heat cutoff $<2.0 \AA$ in all proteins in the validation process. The XP mode to dock was applied.

\section{Results and Discussion}

The synthesized bioactive SPGP, SPGP1-SPGP15 (22-oxocholestane compounds) through an acetolysis opening of the spiroketal framework of spirostan steroids 
has been reported by our research group [9] [11]. Various modifications at A, B and $\mathrm{C}$ rings and at C-26 were introduced (Figure 2): at C-3 an acetoxy, or an $\alpha, \beta$-unsaturated ketone group is found. At ring $\mathrm{B}$, a double bond at C-5 or a ketone group at C-6 is present. At ring $\mathrm{C}$, the presence of a carbonyl group at C-12 was studied. Ring $\mathrm{D}$ was derivatized by the introduction of an acetoxy or a ketone group at $\mathrm{C}-16$. The 22-oxocholestane side chain was modified introducing oxygenated groups at C-26 or introducing a trans diol at C-22 and C-23; similar function present in natural brassinosteroids [37].

Two enzymes associated with fungal proliferation were studied: chitinase B, which is responsible for the regulation of chitin in the fungus, and 1,3- $\beta$-glucanase [38]. Both enzymes are associated with the hydrolysis of 1,3 - and 1,6- $\beta$-glucan (Figure 2). For the case of chitinase B, the chitin fragment has a better coupling energy than most plant growth promoters: SPGP13, SPGP7 and SPGP1 have better energy than the reference inhibitor (FO0), while SPGP12 presents the same level. For Glucanase, the SPGP15 compound has a greater affinity for the enzyme than 1,3-Glucane and Apegin, while SPGP7 has the same energy the substrate (Figure 3).

The AVR4 and ECP6 effectors are responsible for the intramolecular regulation and protection of chitin, so the bound to the active site of this is essential for fungal non-proliferation. For AVR4, SPGP1 and SPGP6 compounds have a higher energy than the Chitin fragment that binds at the site, while in the case of

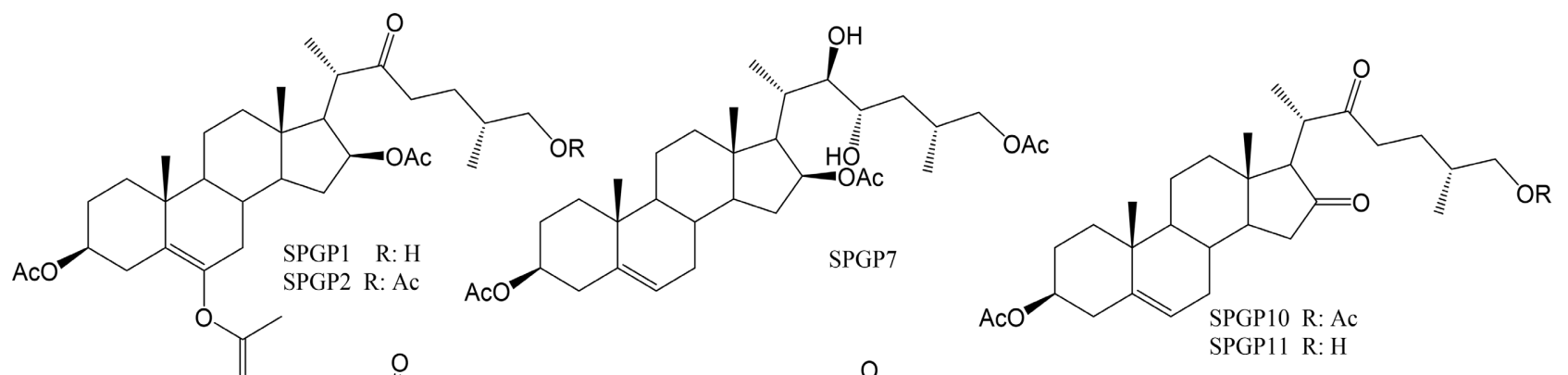

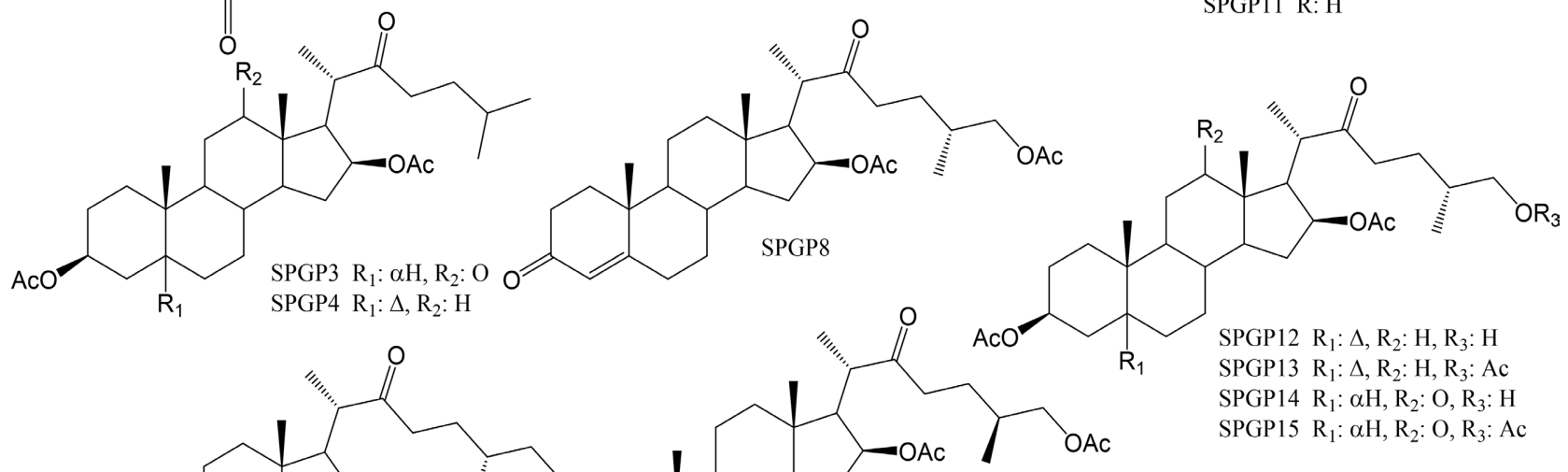

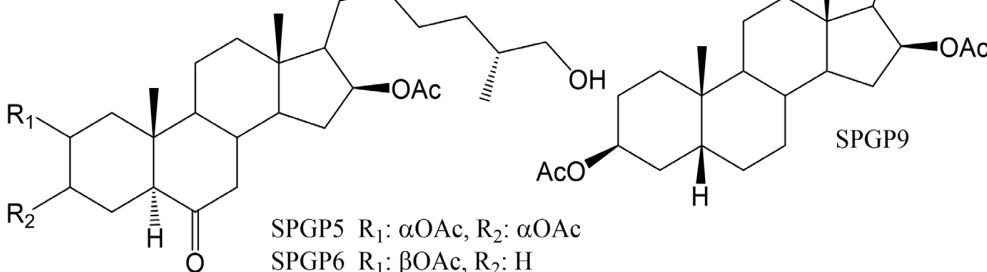

Figure 2. SPGPs evaluated in silico of antifungal targets. 


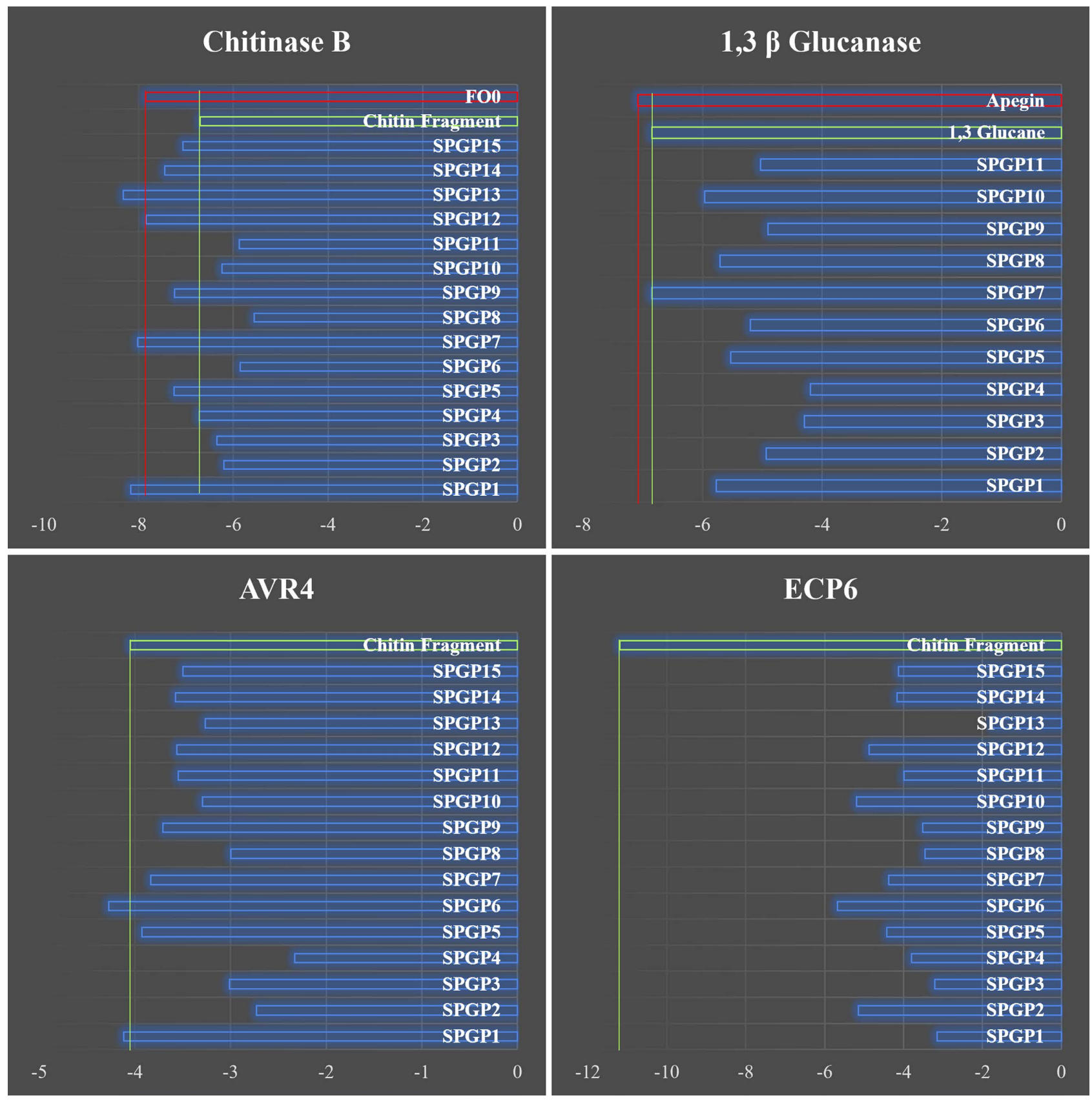

Figure 3. Docking score (kcal/mol) of SPGP in Chitinase B and 1,3- $\beta$-Glucanase enzymes and effectors AVR4 and ECP6.

ECP6, no steroidal derivative has the potential to bound to the active site of this protein. This study is at the energy level, which in the cases of the enzyme has previously established a direct relationship between the coupling energy and the enzyme inhibition constant [39], but they should be studied accordingly to the amino acid residues interact.

\subsection{Chitinase B}

Chitinase B is a chitinolytic enzyme responsible for the regulation of chitin levels in the invading fungus. Chitin is an essential protein (natural substrate) for fun- 
gus proliferation. Herein, the first objective is to evaluate a DS between SPGP and Chitin, compared to the reference inhibitor, to delimit its potential. It was found that both Chitin and SPGP can be placed in the catalytic site; this fact validates the docking and the inhibitory potential of the steroid derivatives. The steroidal nuclei are hydrophobic compared to Chitin fragment one, as confirmed in Figure 4. The potential inhibitory effect can be observed with interacting amino acids, showing the formation of characteristic hydrogen bridges with TRP97, TRP145 and ASP215. These interactions can be observed in both the chitin fragment and the reference inhibitor. Most of the steroidal derivatives present hydrogen bridges with TRP97, even that the compounds with the best DS also present with TRP145, and in some cases with others such as GLH144 (Figure 4).

The van der Waals and $\pi$-alkyl interactions are due to the acetyl groups of the substrate; this fact reveals importance highlighting the lipophilic character of the SPGP derivatives. The hydrophobic caracter of the rings let to observe interactions with with PHE191, TYR145, TRP97 and PHE190 in the case of SPGP13, SPGP7 and SPGP1 (Table 2). SPGP7 there is a hydrogen bridge with TRP220, as well as SPGP12, which has better DS than chitin but not than the reference inhibitor, demonstrating the importance of this residue.
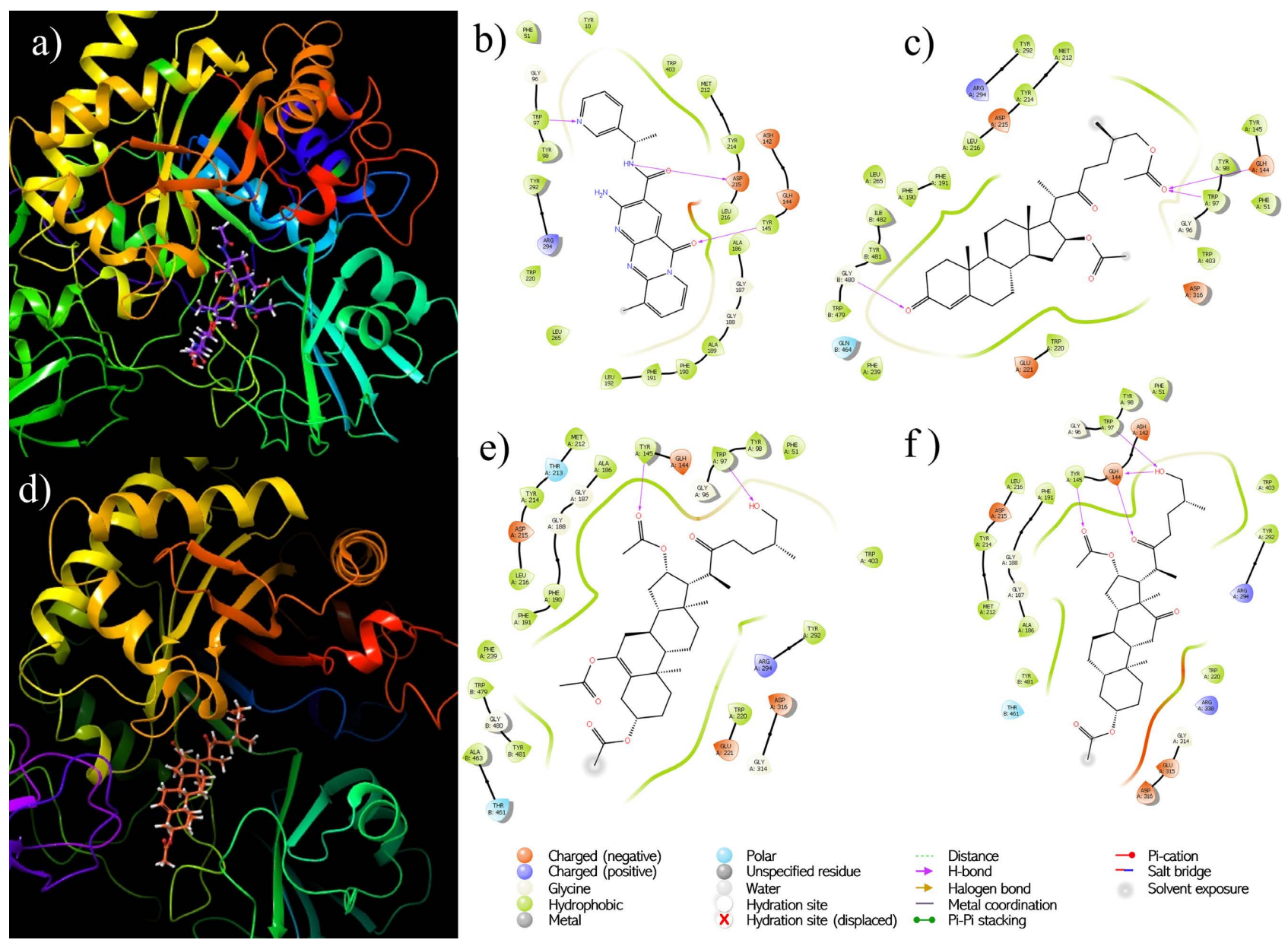

f)

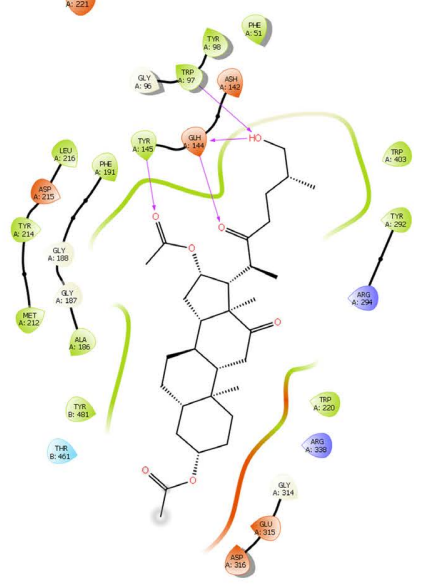

Figure 4. Binding mode in Chitinase B. (a) Chitin Fragment, (b) FO0, (c) SPGP8, (d) SPGP15, (e) SPGP1, (f) SPGP14. 
A. Carrasco-Carballo et al.

Table 2. Interaction of amino acid residues to SPGP at the Chitinase B catalytic site.

\begin{tabular}{|c|c|c|c|}
\hline Compoun & Van der Waals and Pi-Alkyl & $\begin{array}{l}\text { Conventional } \\
\text { Hidrogen Bond }\end{array}$ & Others \\
\hline Chitin & ALA A:145 PHE A:191 TYR A:145 TRP A:97 LEU A:265, PHE A:190 & GLY A:187 GLY A:188 & TYR B: 481 \\
\hline Fragment & LEU A:216 GLU A:144 TYR A:214 MET A:212 & ASP A:215 TRP A:220 & \\
\hline SPGP1 & $\begin{array}{l}\text { ALA A:186 ARG A:294 ASP A:215 ASP A:316 GLU A:315 GLY A:188 } \\
\text { GLY A:314 ILE A:339 LEU A:216 MET A:212 PHE A:190 PHE A:191 } \\
\text { PRO A:317 TRP A:97 TYR A:318 TYR B:481 }\end{array}$ & $\begin{array}{l}\text { TRP A:220 GLY A:187 } \\
\text { ARG A:338 }\end{array}$ & $\begin{array}{l}\text { TRP A:220, ASP } \\
\text { A:336 }\end{array}$ \\
\hline SPGP2 & $\begin{array}{l}\text { ARG A:294 TRP A:97 ASP A:215 TRP A:220 GLU A:144 GLY A:95 GLY } \\
\text { A:96 MET A:212 PHE A:12 PHE A:191 PHE A:51 PRO A:14 TYR A:145 } \\
\text { TYR A:214 TYR A:98 TYR A:99 TYR B:481 }\end{array}$ & TRP A:97 & TRP A:403 \\
\hline SPGP3 & $\begin{array}{l}\text { ASP A:215 PHE A:12 GLU A:144 PHE A:51 GLY A:96 TRP A:97 MET } \\
\text { A:212 PHE A:191 TYR A:214 TYR A:98 TYR A:99 }\end{array}$ & & $\begin{array}{l}\text { TRP A:97, TRP } \\
\text { A:403, TRP A:220 }\end{array}$ \\
\hline SPGP4 & $\begin{array}{l}\text { ARG A:194 ILE B:482 ASP A:316 TRP A:220 GLU A:221 TRP A:97 } \\
\text { GLY A:314 TRP B:479 GLY B:480 TYR B:481 PHE A:190 PHE A:239 } \\
\text { THR B:483 }\end{array}$ & TRP A:97 & $\begin{array}{l}\text { PHE A:191, TRP } \\
\text { B:479 }\end{array}$ \\
\hline SPGP5 & $\begin{array}{l}\text { ALA A:186 ARG A:338 ASP A:215 ASP A:316 ASP A:336, GLY A:187 } \\
\text { ILE A:339 LEU A:216 MET A:212 PHE A:190, PHE A:191 PRO A:219 } \\
\text { PRO A:313 TRP A:220 TRP A:97 TYR A:145 }\end{array}$ & ARG A:294 & $\begin{array}{l}\text { GLY A:188, GLY } \\
\text { A:314 }\end{array}$ \\
\hline SPGP6 & $\begin{array}{l}\text { ALA A:186 TRP A:220 ALA A:217 ARG A:294 GLU A:315 GLY A:188 } \\
\text { GLY A:314 LEU A:216 LEU A:265 MET A:212 PHE A:190 PHE A:191 } \\
\text { TRP A:97 TYR A:145 TYR A:214 TYR B:481 }\end{array}$ & $\begin{array}{l}\text { ASP A:215, ASP } \\
\text { A:316, } \\
\text { GLY A:187 }\end{array}$ & $\begin{array}{l}\text { TRP A:220, GLU } \\
\text { A:221 }\end{array}$ \\
\hline SPGP7 & $\begin{array}{l}\text { ASP A:215, GLU A:144, GLY A:95, GLY A:96, MET A:212, PHE A:12, } \\
\text { PHE A:191, PHE A:51, TRP A:403, TYR A:214, TRP A:97, TYR A:98, } \\
\text { TYR A:99, }\end{array}$ & TRP A:220 & \\
\hline SPGP8 & $\begin{array}{l}\text { ARG A:294 TRP A:220 ARG A:338 ASP A:215 ASP A:316, GLY A:314 } \\
\text { GLY B:480 ILE B:482 PHE A:190 THR B:483, TYR A:145 TYR B:481 }\end{array}$ & ARG A:194 TRP B:479 & $\begin{array}{l}\text { PHE A:191 TRP } \\
\text { A:220 }\end{array}$ \\
\hline SPGP9 & $\begin{array}{l}\text { ALA A:186 TRP A:220 ARG A:294 ARG A:338 ASP A:215, ASP A:316 } \\
\text { ASP A:336 GLU A:315 GLY A:188 GLY A:314 ILE A:339 LEU A:216 } \\
\text { LEU A:265 MET A:212 PHE A:190 PHE A:191, TRP A:97 TYR A:145 } \\
\text { TYR B:481 }\end{array}$ & $\begin{array}{l}\text { GLY A:187, TRP } \\
\text { A:220 }\end{array}$ & TRP A:220 \\
\hline SPGP10 & $\begin{array}{l}\text { ASP A:215 PHE A:191 GLU A:221 GLY A:96 GLY B:480, MET A:212 } \\
\text { PHE A:51 TRP A:220 TRP B:479 TYR A:214, TYR A:99 TYR B:481 }\end{array}$ & TRP A:98 & $\begin{array}{l}\text { PHE A:190 TRP } \\
\text { A:87 TRP A:403, } \\
\text { GLU A:144 }\end{array}$ \\
\hline SPGP11 & $\begin{array}{l}\text { ALA B:491 TYR B:481 ASP A:316 ASP B:489 GLY B:480 ILE B:482 SER } \\
\text { B:484 THR B:483 TRP A:220 TRP B:479 }\end{array}$ & ARG A:194 TRP A:97 & $\begin{array}{l}\text { PHE A:191, PHE } \\
\text { A:190 }\end{array}$ \\
\hline SPGP12 & $\begin{array}{l}\text { ARG A:294, ASP A:215, ASP A:316, ASP A:336, GLY B:480, ILE A:339, } \\
\text { PHE A:190, PHE A:191, TRP A:97, TRP B:479, TRP B:481, TYR A:481, } \\
\text { PHE A:190, TRP A:220 }\end{array}$ & $\begin{array}{l}\text { ARG A:338, GLU } \\
\text { A:221, TRP A:220 }\end{array}$ & $\begin{array}{l}\text { PHE A:190, TRP } \\
\text { A:220 }\end{array}$ \\
\hline SPGP13 & $\begin{array}{l}\text { ARG A:294, ASP A:215, ASP A:316, ASP A:336, GLY B:480, ILE A:339, } \\
\text { ILE B:482, PHE A:190, PHE A:191, THR B:483, TRP A:97, TYR B:481, } \\
\text { TRP A:220 }\end{array}$ & $\begin{array}{l}\text { ARG A:194, ARG } \\
\text { A:338, TRP B:479 }\end{array}$ & \\
\hline SPGP14 & $\begin{array}{l}\text { ASP A:215 TRP A:97 GLU A:144 GLY A:96 MET A:212 PHE A:12 PHE } \\
\text { A:191 PHE A:51 TYR A:214 TYR A:98 TYR A:99 }\end{array}$ & GLY A:95 & $\begin{array}{l}\text { TRP A:220, TRP } \\
\text { A:403, TRP A:97 }\end{array}$ \\
\hline SPGP15 & $\begin{array}{l}\text { ASP A:215 TRP A:97 GLU A:144 GLY A:95 GLY A:96 MET A:212 PHE } \\
\text { A:12 PHE A:191 PHE A:51 TRP A:403 TYR A:214 TYR A:98 TYR A:99 }\end{array}$ & & $\begin{array}{l}\text { TRP A:97, TRP } \\
\text { A:220 }\end{array}$ \\
\hline
\end{tabular}




\section{2. $1,3-\beta$-Glucanase}

The main function of 1,3- $\beta$-Glucanase lies in the hydrolysis of these glucans, necessary for the adaptation-proliferation process of phytpathogen. It is a so specific enzyme that there are only a few selective inhibitors, such as Apegin. The formation of a hydrogen bridge between the residue TYR29 and GLU192 is crucial in the catalytic process of the breakdown of b-glucan into monosaccharide units.

The hydrophobic nature of the steroid nuclei hinders the interaction with the catalytic site of the enzyme (Figure 5). SPGP7 and SPGP15 interact in a polar way with the amino acids GLH 27 and ASP 145 due to its polyoxygenated functions. The latter is important to be underlined in the glucanase hydrolysis process, having a mechanism like Apegin, with the advantage that these SPGP interact with PHE258 and ASN191. SPGP15 also interacts with PHE144. For the case of phytopathogen glucanase-dependent SPGP7 and SPG15, demonstrated the need for a high polarity to bind to this enzyme. Chitinase B, that Chitin, by having acetyl groups, the residues in the protein have a hydrophobic character.

The rest of SPGP $(1-6,8-14)$ have docking scores between $-6.0 \mathrm{kcal} / \mathrm{mol}$ to $-4.0 \mathrm{kcal} / \mathrm{mol}$ (Table 3 ). These values are not comparable to glucans or commercial inhibitors. This is not necessarily negative, since $1,3-\beta$-Glucanase is present not only in phytopathogens, but also in beneficial fungi for plant development, which allows the use of these SPGPs with a plant growth promoting effect without altering the symbiosis with the kingdom fungi.
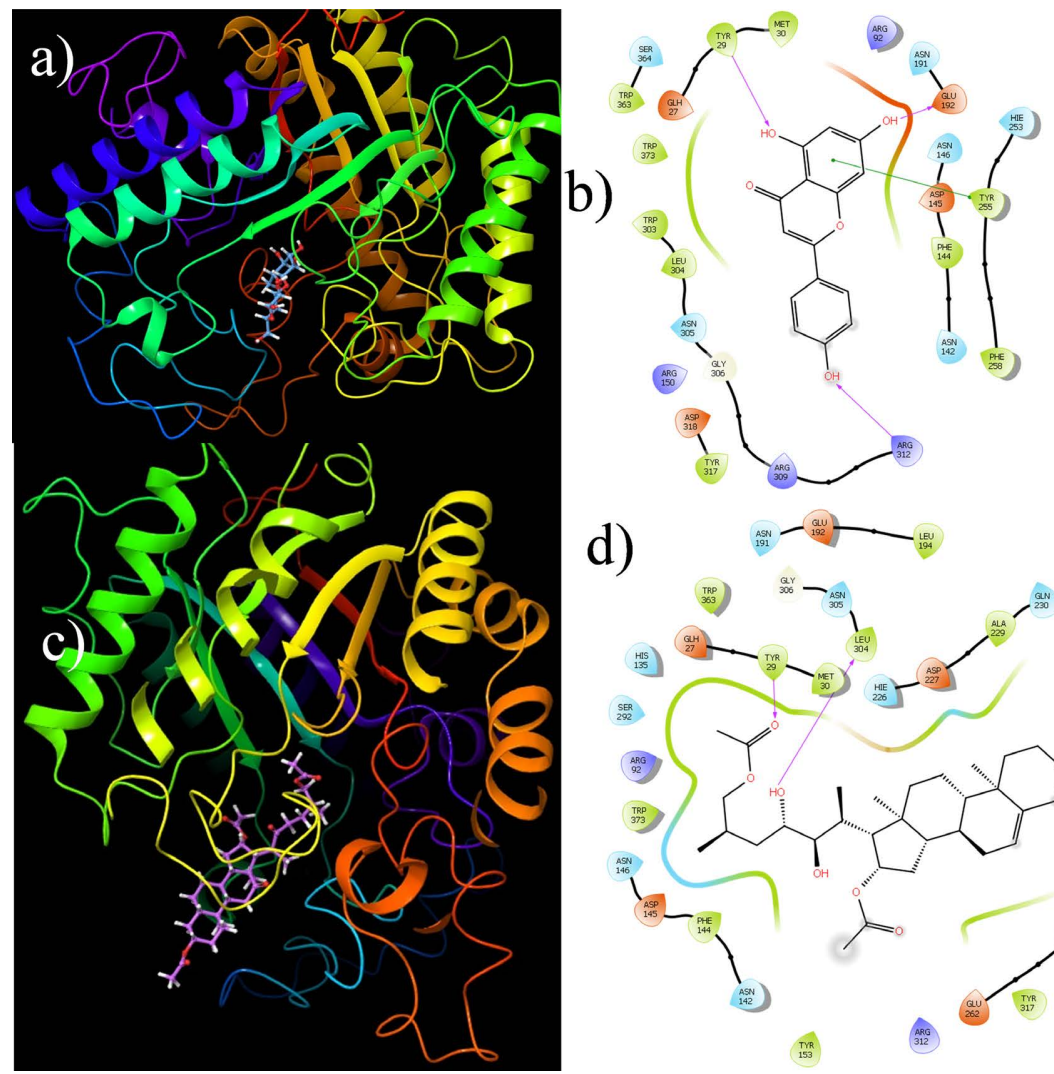
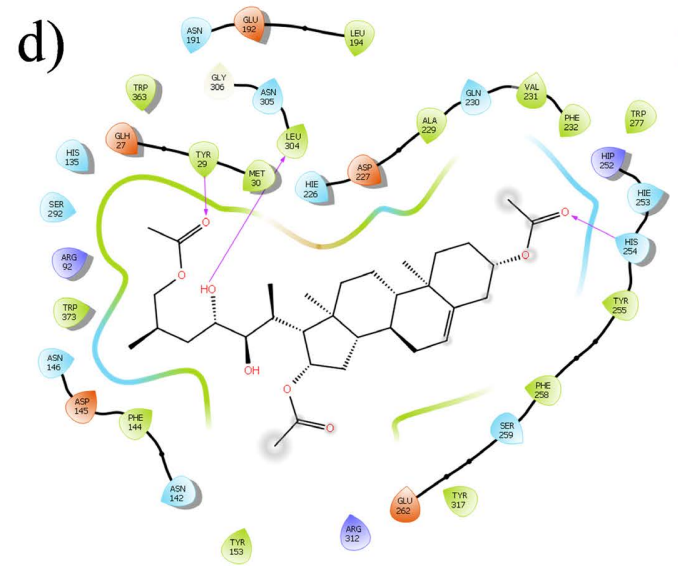

Charged (negative) Charged (positive) Glycine Hydrophobic Metal Polar Unspecified residue Water Hydration site $\times$ Hydration site (displaced)

-... Distance

$\rightarrow$ H-bond

$\rightarrow$ Halogen bond

- Metal coordination

$\rightarrow$ Pi-Pi stacking

$\rightarrow$ Pi-cation

- Salt bridge Solvent exposure

Figure 5. Interaction 1,3- $\beta$-Glucanase: (a) 1,3- $\beta$-Glucane, (b) Apegin, (c) SPGP15, (d) SPGP7. 
A. Carrasco-Carballo et al.

Table 3. Amino acid residues interacting to SPGP at the catalytic site of $1,3-\beta$-Glucanase.

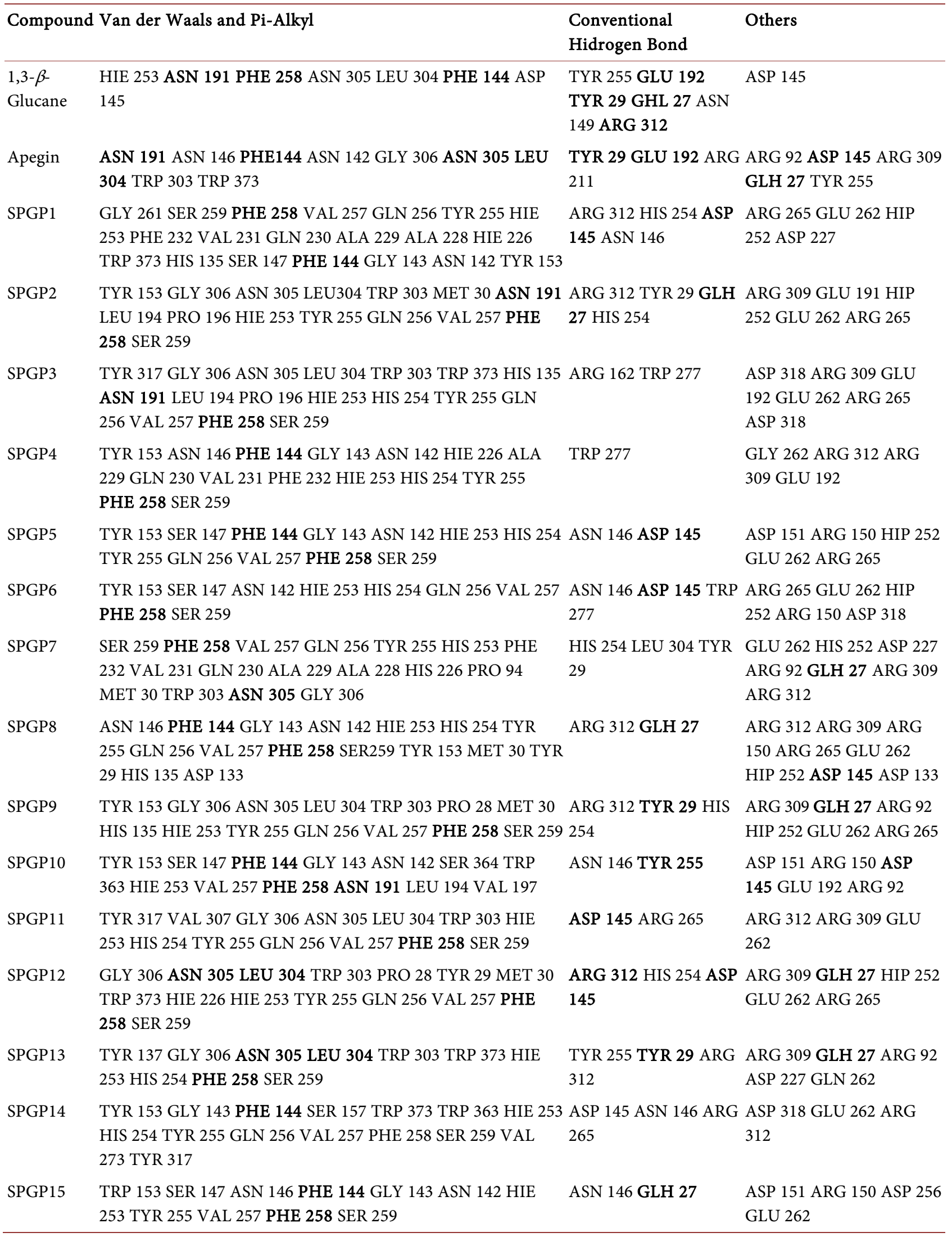




\subsection{ECP6 and AVR4}

Given that the regulation observed is via Chitinase B, it was interesting to study the effectors by the fungus necessary for fungal proliferation, with ECP6 and AVR4 being critical for the transport and proliferative process via Chitin, an indirect regulation option is by allosterically blocking the site. of transport that is located between two chains both in the ECP6 and the AVR4 (Figure 6(a) and Figure 6(d)). At the energy level, we can observe that only 2 compounds have a higher energy than the chitin fragment in the case of AVR4, but in ECP6 no compound has a competitive energy. At the spatial level we can see that the Chitin fragment in both cases is in the middle of the two chains, the SPGP in all cases bind at that site (Figure 6(b) and Figure 6(e)), but particularly in the case of ECP6 this region inter-chains are highly hydrophilic, so the steroidal nucleus being lipophilic does not allow a strong interaction with the site, although acetates and hydroxyls form hydrogen bonds is not enough to compare with chitin. In the case of AVR4, although chitin is hydrophilic, the site is not completely hydrophilic, presenting interaction with the nucleus and with a carbonyl or a enol at C-6 for SPGP1 and SPGP6 (Figure 6(c) and Figure 6(f)).

At the specific level for AVR4, the compounds interact at the particular site and are supported with an increase in van der Walls and $\pi$-alkyl interactions, as can be seen in Table 4, the amino acids for the chitin fraction are repeated in

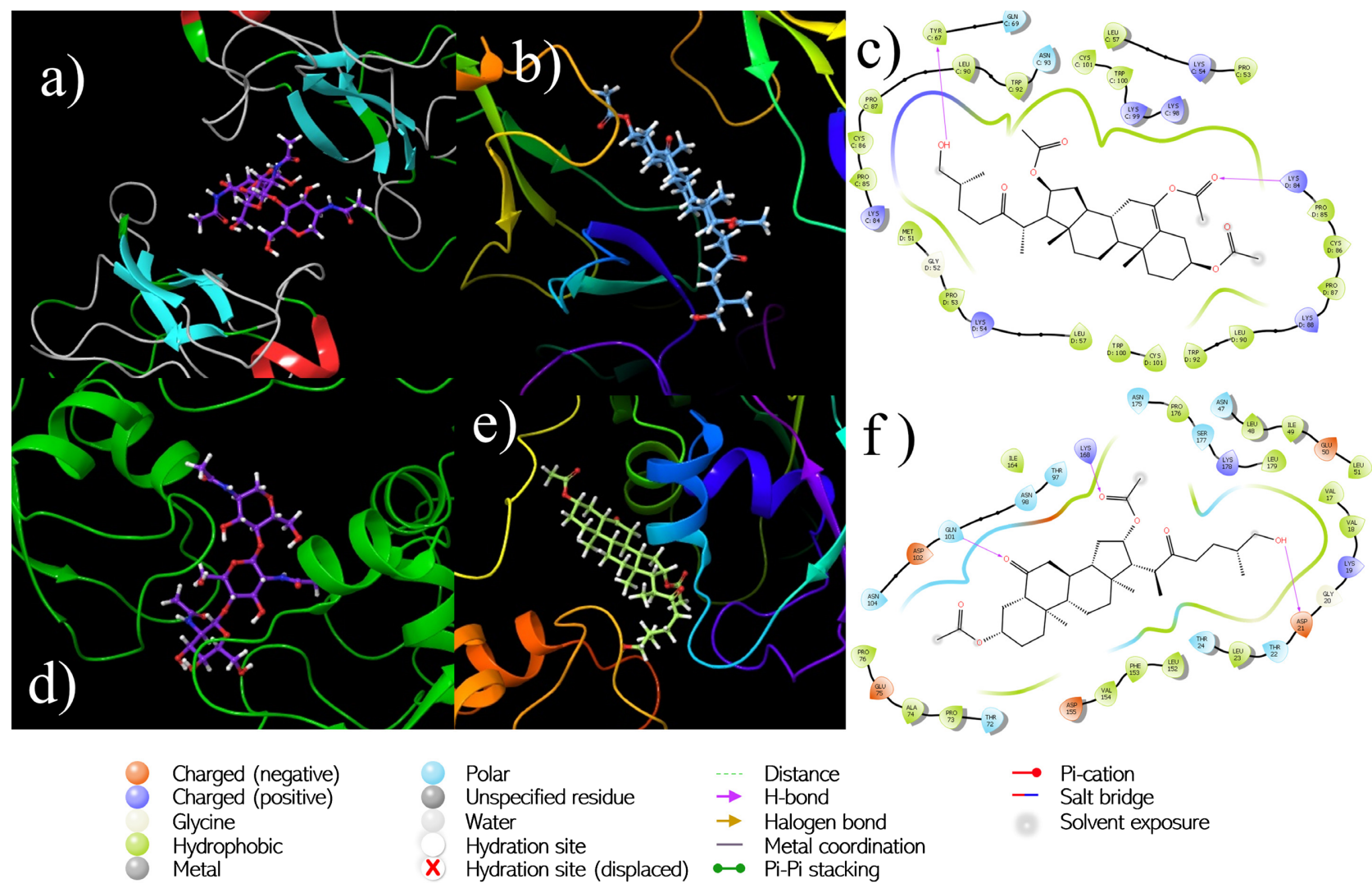

Figure 6. Binding mode for (a) Chitin Fragment vs. ECP6, (b) SPGP6 vs. ECP6, (c) SPGP1 vs. ECP6, (d) Chitin Fragment vs. AVR4, (e) SPGP1 vs. AVR4, (f) SPGP6 vs. AVR4. 
Table 4. Amino acid residues with interaction of SPGP with the catalitic site of AVR4.

\begin{tabular}{ll}
\hline Compound Van der Waals and Pi-Alkyl \\
\hline CPGP1 & CYS C:101, TRP C:100, LEU C:57, PRO C:53, PRO D:85, CYS D:86, PRO \\
& D:87, LEU D:90, TRP D:92, GLN D:69, TYR D:67, CYS D:101, TRP D:100, \\
& LEU D:57, PRO D:53, GLY D:52, MET D:51, PRO C:85, CYS C:86, PRO \\
& C:87, LEU C:98, TRP C:92, ASN C:93, TYR C:67, GLN C:69 \\
SPGP2 & CYS C:50, MET C:51, GLY C:52, PRO C:53, LEU C:57, TYR D:67, GLN \\
& D:69, GLY C:97, TRP C:100, CYS C:101, PRO A:61, SER A:63, CYS \\
& A:64, TRP C:92, LEU C:90, GLY C:89, PRO D:53, PRO C:87, GLY D:52, \\
& CYS C:86, MET D:51, CYS D:50, PRO C:85, VAL C:83, VAL C:82, TYR \\
& C:67, GLN C:69 \\
& PRO D:87, TRP D:100, CYS D:101, LEU D:90, LEU C:106, TYR C:103, \\
ASN C:93, CYS C:101, TRP C:92, TRP C:100, LEU C: 90, MET D:51, \\
PRO C:87, GLY D:52, CYS C:86, PRO D.53, PRO C:85, TYR C:67, GLN \\
C:69, LEU C:57, RPO C:53, GLY C:52, TYR D:67, GLN D:69
\end{tabular}

SPGP4 PRO D:87, LEU D:90, THR A:113, LEU C:106, ASN C:105, TYR C:103, TYR D:103, CYS C:101, TRP D:100, TRP C:100, MET D:51, GLY D:52, PRO D:53, PRO C:85, CYS C:86, PRO C:87, TYR C:67, LEU C:90, TRP C:92, ASN C:93

SPGP5 TYR C:58, LEU C:57, THR C:65, THR C:66, TYR C:67, ILE C:68, GLN C:69, PRO C:53, GLY C:52, TRP C:100, CYS C:101, CYS D:86, GLN D:69, TYR D:67, PRO D:87, TYR C:103, PRO C:104, LEU C:106, TYR D:103, CYS D:101, TRP D:100, GLY D:97, ASN C:93, THR A:113, TRP C:92, GLN C:91, LEU C:90, GLY C:89, LEU D:57, VAL A:111, PRO D:53, PRO C:87, GLY D.52, CYS C:86, PRO C:85, MET D:51, CYS D:50, VAL C:83, VAL C:82, THR D:48

SPGP6

TYR D:67, GLN D:69, LEU C:57, PRO C:53, GLY C:52, CYS D:85, PRO D:87, LEU D:90, TRP D:100, CYS D:101, LEU C:106, TYR C:103, CYS C:101, TRP C:100, ASN C:93, TRP C:92, PRO D.53, GLY D:52, MET D:51, TYR C:67, LEU C:90, GLN C:69, PRO C:87, CYS C:86, PRO C:85

SPGP7 VAL C:82, VAL C:83, PRO C:85, TYR C:67, GLN C:69, CYS C:86, CYS D:50, PRO C:87, MET D:51, GLY D:52, PRO D:53, LEU C:90, LEU C:57, C:85, MET D:51 TRP C:92, GLN D:69, TYR D.67, PRO C:53, LEU D:57, TRP D:92, LEU D:90, PRO D:87, CYS D:86, PRO D:85, CYS D:101. TRP D:100, TRP C:100, CYS C:101

SPGP8

GLN D:69, TYR D:67, PRO C:53, PRO D:87, TRP D:100, CYS D:101, LEU C:57, LEU D:90, TRP D:92, TRP C:100, ASN C:93, TRP C:92, CYS C:98 C:101, TYR C:67, LEU C:90, TYR C:103, LEU C.106, PRO C:87, CYS C:86, CYS D:50, MET D:51, GLY D:52, PRO D:53, LEU D:57

SPGP9

PRO D:85, CYS D:86, LEU D:106, PRO D:87, TYR D:103, TYR D:67, LEU D.90, CYS D:101, TRP D:100, TRP D:92, ASN D:93, THR A:113, TYR C:103, CYS C:101, TRP C:100, PRO C:85, CYS C:86, PRO C:87, LEU C:90, TYR C:67, MET D:51, GLY D:52, PRO D:53, TRP C:92, ASN C:93

SPGP10 GLN D:69, TYR D:67, PRO D:85, CYS D:86, LEU D:106, PRO D:87, TYR D:103, LEU D:90, TRP D:92, ASN D:93, CYS D:101, TRP D:100, TYR C:103, PRO D:53, LEU C:57, TRP C:100, LEU D:57, PRO C:53

\section{Conventional Others}

Hidrogen Bond

LYS D:84, TYR LYS D:84, LYS C:54, LYS

C:67

C:98, LYS C:99, LYS D:88, LYS D:54, LYS C:84

LYS C.84, TYR LYS C:54, ASP C:55, LYS

C:67, LYS C:54 D:84, LYS C:98, LYS C:99, ASP A:62, CL A:208, ASP D:55, LYS D:54, LYS C:88, LYS C:84

LYS D:84, ASP C:102, LYS C:99, LYS C:98, LYS C:84, ASP C.55, LYS C:54

LYS A:112, ASP C:102, LYS C:98

LYS C:84, MET ASP C:55, LYS C:54, LYS $\mathrm{D}: 51$ C:98, LYS C.99, LYS C:84, ASP C:102, ASP D:102, LYS C:88, LYS C:54, LYS D.49, LYS C:84

LYS C:98, ASP C:102, TYR

LYS C:54, LYS D:84, ASP C:102, LYS C:99, LYS C:98, LYS C:84 C:67

LYS C:84, LYS C:88, LYS D:54, ASP D:55, LYS C:54, LYS D:84

TYR D:67, LYS LYS D:84, LYS C:54, LYS D:99, LYS C:98, LYS C:99, ASP C:102, LYS D:54, ASP D:55

CYS D:101, LYS ASP D:102, LYS D:99, D:98 LYS D:98, ASP C:102, LYS D:99, LYS D:54

LYS D:84, CYS LYS D:84, ASP D:102, D:101, LYS D:98 LYS D:99. LYS D:98, LYS D:54, LYS C:99, LYS C:98, LYS C:54 


\begin{tabular}{|c|c|c|c|}
\hline \multicolumn{4}{|c|}{ Continued } \\
\hline SPGP11 & $\begin{array}{l}\text { PRO D.85, PRO D:87, TYR D:67, GLN D:69, TRP C:92, LEU C:90, PRO } \\
\text { C:87, CYS C:86, PRO C:85, PRO D:53, GLY D:52, MET D:51, CYS D:50, } \\
\text { GLN C:69, TYR C:67, LEU C:57, PRO C:53, CYS C:101, TRP C:100, } \\
\text { GLY C:97 }\end{array}$ & $\begin{array}{l}\text { LYS C:84, MET } \\
\text { D:51 }\end{array}$ & $\begin{array}{l}\text { LYS D:84, LYS C:84, ASP } \\
\text { C:102, LYS C:99, LYS } \\
\text { C:54, LYS C: } 98\end{array}$ \\
\hline SPGP12 & $\begin{array}{l}\text { MET D:51, GLY D:52, PRO D:53, LEU D:57, TYR C:67, GLN C:69, PRO } \\
\text { C:53, PRO C:85, CYS C:86, PRO C:87, LEU C:90, TRP C:92, GLN D:69, } \\
\text { TRP D:92, CYS D:101, LEU C:57, PRO D:85, CYS D:86, PRO D:87, }\end{array}$ & $\begin{array}{l}\text { LYS C:54, TYR } \\
\text { D:67 }\end{array}$ & $\begin{array}{l}\text { LYS C:84, LYS D:54, ASP } \\
\text { D:55, LYS C:54, LYS } \\
\text { D:84, LYS C:98, LYS C:99, } \\
\text { ASP C:102 }\end{array}$ \\
\hline SPGP13 & $\begin{array}{l}\text { MET D:51, GLY D:52, PRO D:53, PRO D:87, LEU D:106, LEU D:90, } \\
\text { TYR D:103, ASN D:93, CYS D:101, TRP D:100, THR A:113, TYR C:103, } \\
\text { TRP C:92, LEU C:90, CYS C:101, PRO C:53, TRP C:100, PRO C:87, CYS } \\
\text { C:86, LEU C:57, PRO C:85, TYR C:67 }\end{array}$ & LYS D:98 & $\begin{array}{l}\text { LYS D:54, ASP D:102, } \\
\text { LYS D:98, ASP C:102, } \\
\text { LYS C:99, LYS C:54, LYS } \\
\text { C:98, LYS C: } 84\end{array}$ \\
\hline SPGP14 & $\begin{array}{l}\text { TYR C:67, TRP C:100, CYS C:101, TYR C:103, PRO D:87, LEU D:106, } \\
\text { LEU D:90, TYR D:103, ASN D:93, CYS D:101, TRP D:100, THR A:113, } \\
\text { VAL A:111, PRO D:53, TRP C:92, LEU C:90, PRO C:87, CYS C:87, CYS } \\
\text { C:88, PRO C:85 }\end{array}$ & $\begin{array}{l}\text { CYS C:101, ASP } \\
\text { D:102, LYS D:98 }\end{array}$ & $\begin{array}{l}\text { LYS C: } 99, \text { ASP C: } 102, \\
\text { LYS A:112, LYS D:54, } \\
\text { LYS C: } 84\end{array}$ \\
\hline SPGP15 & $\begin{array}{l}\text { PRO C:53, GLN D:69, TYR D:67, PRO D:85, LEU D:106, CYS D:86, } \\
\text { PRO D:87, TYR D:103, LEU D:90, CYS D:101, TRP D:92, TRP D:100, } \\
\text { ASN D:93, THR A:113, TYR C:103, PRO C:87, CYS C:101, TRP C:100, } \\
\text { LEU C:90, LEU D:57, PRO D:53, GLY D:52 }\end{array}$ & $\begin{array}{l}\text { TYR D:67, LYS } \\
\text { D:98 }\end{array}$ & $\begin{array}{l}\text { LYS D:84, ASP D:102, } \\
\text { LYS D:99, LYS D:98, LYS } \\
\text { D:54 }\end{array}$ \\
\hline
\end{tabular}

interaction for derivatives SPGP, but in the formation of hydrogen bridges is where it is key for SPGP1 and SPGP6 since they interact with TYR D: 67, as well as annexing TYR C: 67, ASP C: 102 and LYS C: 98, which its increases the coupling energy allowing it to compete in the case of SPGP1 at the same energy level and for SPGP6 with a better DS than the endogenous ligand, thus allowing the AVR4 effector to be blocked.

\section{Conclusion}

SPGPs compounds have a huge plant growth promoting effect in various biological systems, and an effect against phytopathogens (specifically for Chitinase $\mathrm{B}$ and $1,3-\beta$-Glucanase). Some SPGPs were studied in silico finding 5 competitive inhibitors better than Chitin and 4 preferred than $\mathrm{FO} 0$ (reference inhibitor). While for 1,3- $\beta$-Glucanase, 2 potential inhibitors were found (SPGP7 at the level of 1,3- $\beta$-glucane and SPGP15) having a better activity than Apegin (reference inhibitor). For the blockage of chitin effectors (AVR4 and ECP6), only an allosteric blockade against AVR4 was achieved, so the 22-oxocholestan studied compounds have a latent potential as inhibitors of fungal proliferation at the enzymatic level. In conclusion, SPGPs have a potential dual action, as promoters for plant growth and as antifungal against phytopagens.

\section{Acknowledgements}

S.R.J. was supported by BUAP (Grant 100127777-VIEP2021) and CONACYT (Grant PRONACES 317580); C.C.A., H.M.J.C., and C.B.L. acknowledge CONACYT 
for grants 698207, 406753, and PRODEP 511-6/2019-16022 respectively.

\section{Conflicts of Interest}

The authors declare no conflicts of interest regarding the publication of this paper.

\section{References}

[1] Wang, S.Q., Zhao, H.H., Zhao, L.M., Gu, C.M., Na, Y.G., Xie, B., Cheng, S.H. and Pan, G.J. (2020) Application of Brassinolide Alleviates Cold Stress at the Booting Stage of Rice. Journal of Integrative Agriculture, 19, 975-987.

https://doi.org/10.1016/S2095-3119(19)62639-0

[2] Hussain, M.A., Fahad, S., Sharif, R., Jan, M.F., Mujtaba, M., Ali, Q., Ahmad, A., Ahmad, H., Amin, N., Ajayo, B.S., Sun, C., Gu, L., Ahmad, I., Jiang, Z. and Hou, J. (2020) Multifunctional Role of Brassinosteroid and Its Analogues in Plants. Plant Growth Regulation, 92, 141-156. https://doi.org/10.1007/s10725-020-00647-8

[3] Hafeez, M.B., Zahra, N., Zahra, K., Raza, A., Khan, A., Shaukat, K. and Khan, S. (2021) Brassinosteroids: Molecular and Physiological Responses in Plant Growth and Abiotic Stresses. Plant Stress, 2, Article ID: 100029.

https://doi.org/10.1016/j.stress.2021.100029

[4] Jia, J., Zhang, Y. and Feng, H. (2019) Effects of Brassinolide on Microspore Embryogenesis and Plantlet Regeneration in Pakchoi (Brassica rapa var. multiceps). Scientia Horticulturae, 252, 354-362. https://doi.org/10.1016/j.scienta.2019.04.004

[5] Peng, J., Tang, X. and Feng, H. (2004) Effects of Brassinolide on the Physiological Properties of Litchi Pericarp (Litchi chinensis cv. Nuomoci). Scientia Horticulturae, 101, 407-416. https://doi.org/10.1016/j.scienta.2003.11.012

[6] Doležalová, J., Koudela, M., Sus, J. and Ptáček, V. (2016) Effects of Synthetic Brassinolide on the Yield of Onion Grown at Two Irrigation Levels. Scientia Horticulturae, 202, 125-132. https://doi.org/10.1016/j.scienta.2016.02.023

[7] Vázquez, M.N., Guerrero, Y.R., González, L.M. and de la Noval, W.T. (2013) Brassinosteroids and Plant Responses to Heavy Metal Stress. An Overview. Open Journal of Metal, 3, 34-41. https://doi.org/10.4236/ojmetal.2013.32A1005

[8] Yadava, P., Kaushal, J., Gautam, A., Parmar, H. and Singh, I. (2016) Physiological and Biochemical Effects of 24-Epibrassinolide on Heat-Stress Adaptation in Maize (Zea mays L.). Natural Sciences, 8, 171-179. https://doi.org/10.4236/ns.2016.84020

[9] Zeferino-Diaz, R., Hilario-Martinez, J.C., Rodriguez-Acosta, M., Carrasco-Carballo, A., Hernandez-Linares, M.G., Sandoval-Ramirez, J. and Fernandez-Herrera, M.A. (2017) Mimicking Natural Phytohormones. 26-Hydroxycholestan-22-One Derivatives as Plant Growth Promoters. Steroids, 125, 20-26. https://doi.org/10.1016/j.steroids.2017.06.004

[10] Zeferino-Diaz, R., Hilario-Martinez, J.C., Rodriguez-Acosta, M., Sandoval-Ramirez, J. and Fernandez-Herrera, M.A. (2015) 22-Oxocholestanes as Plant Growth Promoters. Steroids, 98, 126-131. https://doi.org/10.1016/j.steroids.2015.03.005

[11] Hilario-Martínez, J.C., Zeferino-Díaz, R., Muñoz-Hernández, M.A., Hernández-Linares, M.G., Cabellos, J.L., Merino, G., Sandoval-Ramírez, J., Jin, Z. and Fernández-Herrera, M.A. (2016) Regioselective Spirostan E-Ring Opening for the Synthesis of Dihydropyran Steroidal Frameworks. Organic Letters, 18, 1772-1775. https://doi.org/10.1021/acs.orglett.6b00492 
[12] Balasubramanian, V., Vashisht, D., Cletus, J. and Sakthivel, N. (2012) Plant $\beta-1,3-$ Glucanases: Their Biological Functions and Transgenic Expression against Phytopathogenic Fungi. Biotechnology Letters, 34, 1983-1990. https://doi.org/10.1007/s10529-012-1012-6

[13] Ojito-Ramos, K. and Orelvis, P. (2010) Introducción al sistema inmune en plantas. Biotecnologia Vegetal, 10, 3-19.

https://revista.ibp.co.cu/index.php/BV/article/view/266

[14] Hawkesford, M.J. and Buchner, P. (2001) Molecular Analysis of Plant Adaptation to the Environment. Kluwer Academic Publishers, Dordrecht. https://doi.org/10.1007/978-94-015-9783-8

[15] Heath, M.C. (2000) Nonhost Resistance and Nonspecific Plant Defenses. Current Opinion in Plant Biology, 3, 315-319. https://doi.org/10.1016/S1369-5266(00)00087-X

[16] Shewry, P.R. and Lucas, J.A. (1997) Plant Proteins that Confer Resistance to Pests and Pathogens. Advances in Botanical Research, 26, 135-170, A170, B170, C170, D170, 171-192. https://doi.org/10.1016/S0065-2296(08)60120-2

[17] Lo Presti, L., Lanver, D., Schweizer, G., Tanaka, S., Liang, L., Tollot, M., Zuccaro, A., Reissmann, S. and Kahmann, R. (2015) Fungal Effectors and Plant Susceptibility. Annual Review of Plant Biology, 66, 513-545. https://doi.org/10.1146/annurev-arplant-043014-114623

[18] Bolton, M.D., Van Esse, H.P., Vossen, J.H., De Jonge, R., Stergiopoulos, I., Stulemeijer, I.J.E., Van Den Berg, G.C.M., Borrás-Hidalgo, O., Dekker, H.L., De Koster, C.G., De Wit, P.J.G.M., Joosten, M.H.A.J. and Thomma, B.P.H.J. (2008) The Novel Cladosporium fulvum Lysin Motif Effector Ecp6 is a Virulence Factor with Orthologues in Other Fungal Species. Molecular Microbiology, 69, 119-136. https://doi.org/10.1111/j.1365-2958.2008.06270.x

[19] Gupta, P., Ravi, I. and Sharma, V. (2013) Induction of $\beta$-1,3-Glucanase and Chitinase Activity in the Defense Response of Eruca sativa Plants against the Fungal Pathogen Alternaria brassicicola. Journal of Plant Interactions, 8, 155-161. https://doi.org/10.1080/17429145.2012.679705

[20] Zhao, J., Wang, J., An, L., Doerge, R.W., Chen, Z.J., Grau, C.R., Meng, J. and Osborn, T.C. (2007) Analysis of Gene Expression Profiles in Response to Sclerotinia sclerotiorum in Brassica napus. Planta, 227, 13-24. https://doi.org/10.1007/s00425-007-0586-Z

[21] Shrestha, C.L., Oña, I., Muthukrishnan, S. and Mew, T.W. (2008) Chitinase Levels in Rice Cultivars Correlate with Resistance to the Sheath Blight Pathogen Rhizoctonia solani. European Journal of Plant Pathology, 120, 69-77.

https://doi.org/10.1007/s10658-007-9199-4

[22] Salim, A.P., Saminaidu, K., Marimuthu, M., Perumal, Y., Rethinasamy, V., Palanisami, J.R. and Vadivel, K. (2011) Defense Responses in Tomato Landrace and Wild Genotypes to Early Blight Pathogen Alternaria solani Infection and Accumulation of Pathogenesisrelated Proteins. Archives of Phytopathology and Plant Protection, 44, 1147-1164. https://doi.org/10.1080/03235408.2010.482763

[23] Wu, G.W., Gao, J.M., Shi, X.W., Zhang, Q., Wei, S.P. and Ding, K. (2011) Microbial Transformations of Diosgenin by the White-Rot Basidiomycete Coriolus versicolor. Journal of Natural Products, 74, 2095-2101. https://doi.org/10.1021/np2003484

[24] Sánchez-Rangel, D., Sánchez-Nieto, S. and Plasencia, J. (2012) Fumonisin B1, a Toxin Produced by Fusarium verticillioides, Modulates Maize $\beta$-1,3-Glucanase Activities Involved in Defense Response. Planta, 235, 965-978. 
https://doi.org/10.1007/s00425-011-1555-0

[25] Kuo, H.W., Zeng, J.K., Wang, P.H. and Chen, W.C. (2015) A Novel Exo-Glucanase Explored from a Meyerozyma sp. Fungal Strain. Advances in Enzyme Research, 3, 53-65. https://doi.org/10.4236/aer.2015.33006

[26] Chisholm, S.T., Coaker, G., Day, B. and Staskawicz, B.J. (2006) Host-Microbe Interactions: Shaping the Evolution of the Plant Immune Response. Cell, 124, 803-814. https://doi.org/10.1016/j.cell.2006.02.008

[27] Patrick, W.M., Nakatani, Y., Cutfield, S.M., Sharpe, M.L., Ramsay, R.J. and Cutfield, J.F. (2010) Carbohydrate Binding Sites in Candida albicans Exo- $\beta$-1,3-Glucanase and the Role of the Phe-Phe 'Clamp' at the Active Site Entrance. The FEBS Journal, 277, 4549-4561. https://doi.org/10.1111/j.1742-4658.2010.07869.x

[28] Jiang, P.T. and Yuan, X. (2021) Structure of Serratia marcescens Chitinase B Complexed with Compound 6q. https://www.rcsb.org/structure/7CB1 https://doi.org/10.2210/pdb7cb1/pdb

[29] Hurlburt, N.K., Chen, L.H., Stergiopoulos, I. and Fisher, A.J. (2018) Structure of the Cladosporium fulvum Avr4 Effector in Complex with (GlcNAc) ${ }_{6}$ Reveals the Ligand-Binding Mechanism and Uncouples Its Intrinsic Function from Recognition by the Cf-4 Resistance Protein. PLoS Pathogens, 14, e1007263.

https://doi.org/10.1371/journal.ppat.1007263

[30] Sánchez-Vallet, A., Saleem-Batcha, R., Kombrink, A., Hansen, G., Valkenburg, D.J., Thomma, B.P.H.J. and Mesters, J.R. (2013) Fungal Effector Ecp6 Outcompetes Host Immune Receptor for Chitin Binding through Intrachain LysM Dimerization. eLife, 2, e00790. https://doi.org/10.7554/eLife.00790.013

[31] Madhavi Sastry, G., Adzhigirey, M., Day, T., Annabhimoju, R. and Sherman, W. (2013) Protein and Ligand Preparation: Parameters, Protocols, and Influence on Virtual Screening Enrichments. Journal of Computer-Aided Molecular Design, 27, 221-234. https://doi.org/10.1007/s10822-013-9644-8

[32] Schrödinger Release 2021-3: Protein Preparation Wizard; Epik, Schrödinger, LLC, New York, NY, 2021; Impact, Schrödinger, LLC, New York, NY; Prime, Schrödinger, LLC, New York, NY.

[33] Lu, C., Wu, C., Ghoreishi, D., Chen, W., Wang, L., Damm, W., Ross, G.A., Dahlgren, M.K., Russell, E., Von Bargen, C.D., Abel, R., Friesner, R.A. and Harder, E.D. (2021) OPLS4: Improving Force Field Accuracy on Challenging Regimes of Chemical Space. Journal of Chemical Theory and Computation, 17, 4291-4300. https://doi.org/10.1021/acs.jctc.1c00302

[34] Schrödinger Release 2021-3: LigPrep, Schrödinger, LLC, New York, NY.

[35] Friesner, R.A., Murphy, R.B., Repasky, M.P., Frye, L.L., Greenwood, J.R., Halgren, T.A., Sanschagrin, P.C. and Mainz, D.T. (2006) Extra Precision Glide: Docking and Scoring Incorporating a Model of Hydrophobic Enclosure for Protein-Ligand Complexes. Journal of Medicinal Chemistry, 49, 6177-6196. https://doi.org/10.1021/jm051256o

[36] Schrödinger Release 2021-3: Glide, Schrödinger, LLC, New York, NY.

[37] Moreno-Castillo, E., Ramírez-Echemendía, D.P., Hernández-Campoalegre, G., Mesa-Tejeda, D., Coll-Manchado, F. and Coll-García, Y. (2018) In Silico Identification of New Potentially Active Brassinosteroid Analogues. Steroids, 138, 35-42. https://doi.org/10.1016/j.steroids.2018.06.009

[38] Wang, Y., Liu, M., Wang, X., Zhong, L., Shi, G., Xu, Y., Li, Y., Li, R., Huang, Y., Ye, X., Li, Z. and Cui, Z. (2021) A Novel $\beta$-1,3-Glucanase Gns6 from Rice Possesses An- 
tifungal Activity against Magnaporthe oryzae. Journal of Plant Physiology, 265, Article ID: 153493. https://doi.org/10.1016/j.jplph.2021.153493

[39] Xu, X., Song, Z., Yin, Y., Zhong, F., Song, J., Huang, J., Ye, W. and Wang, P. (2020) Virtual Screening of Inhibitors for Chitosanases EAG1. Advances in Enzyme Research, 8, 49-57. https://doi.org/10.4236/aer.2020.84005 